\title{
Characterization of Clays in Catalan Potash Basin. Influence on the Geomechanicalconditions in Potash Mining
}

\author{
Nor Sidki, Marc Bascompta, Lluís Sanmiquel, David Parcerisa, Pura Alfonso, Gabriel R. González- \\ Jiménez. \\ Department of Mining Engineering, Industrial and ICT.
}

All the authors are from the Polytechnic University of Catalonia (UPC), Avenue Bases de Manresa, 61-73, 08242-Manresa (Barcelona).

nor.sidki@upc.edu; marc.bascompta@upc.edu; lluis.sanmiquel@upc.edu; david.parcerisa@upc.edu; maria.pura.alfonso@upc.edu; grgj29@gmail.com

\section{Extended Abstract}

Cabanasas mine is a potash ore deposit located in the Spanish Ebro Basin, it is configured by 8 salt lithologies separated by layers of clays. These clays are considered to be the weakest levels forming great surfaces all over the deposit, being the most likely zones to detach and, therefore, cause accidents.

Furthermore, in recent years, mine infrastructure is reaching considerable depths, opening underground excavations at more than 900 meters deep. Consequently, making work conditions every day more dangerous. Therefore, it is crucial to analyze the geomechanical properties of each saline lithology as well as clays composition and texture.

In this regard, SEM-EDS analyses and X-Ray will be performed to determine the compositions and texture of each lithology. Moreover, geomechanical test will be performed in order to quantify the cohesion between saline and clay materials. These analyses would increase the knowledge of the geomechanical characteristics. Improving the safety conditions and the production operations. 